As well as being annoying, environmental tobacco smoke has been cited as the cause of in flight headaches; eye, nose, and throat irritation; and breathing problems. In a recent paper, however, the authors argued that coexisting factors such as a low relative humidity, high ozone concentrations, and even hypoxia could equally well be to blame and that evidence to the contrary was not available. ${ }^{6}$ Of more serious concern is the possibility of a link between environmental tobacco smoke and lung cancer. ${ }^{7}$ Studies, however, have not so far supported a relation between environmental tobacco smoke (as measured by levels of carbon monoxide and respirable suspended particulates) and chronic ill health of any kind. Furthermore, although increased ventilation and filtration may improve air quality, the volume and flow of circulating air are already high, and segregation of passengers who smoke seems to be reasonably effective in reducing complaints about environmental tobacco smoke during flights. Of course, a total ban on smoking on all aircraft would instantly improve matters subjectively, and such measures are being considered.

Finally, even with the approximate halving in the volume of fresh air entering the cabin, there remains more than enough oxygen for human consumption (estimated at less than 0.003 $\mathrm{m}^{3}$ per person per minute) at a pressure equivalent to that at an altitude of $2440 \mathrm{~m}$, which is the pressure normally maintained in the cabins of commercial aircraft. Nevertheless, even this reduction in pressure leads to a small desaturation of haemoglobin in healthy people. So although the National Academy of Sciences has deemed such a pressure-altitude to be "generally adequate to protect the travelling public,"s pressurisation to below this is to be encouraged so that those with compromised cardiorespiratory physiology are further protected from the effects of even the mild hypoxia experienced at normal cabin altitudes. ${ }^{9}$

Thus, the general malaise associated with air travel is probably multifactorial in nature, with the quality of cabin air undoubtedly contributing. But other considerations such as the motion of the aircraft, jet lag, and even the difficulties associated with airport procedures cannot be ignored. It is reasonable to conclude that environmental tobacco smoke and other cabin contaminants do not represent a great threat to health.

RICHARD HARDING

RAF consultant in aviation medicine

RAF Institute of Aviation Medicine,

Farnborough,

Hampshire GU14 6SE

\footnotetext{
1 Gloag D. Making air crashes more survivable. BMf 1992;304:1325-6.

2 Space D. Cabin air quality. Airliner 1993;Oct-Dec:19-24.

3 Minerva. Views. $B M 7$ 1988;296:362.

4 Smith A. Smoke free flying. $B M Y$ 1988:297:1001.

5 Geomet Technologies. Airliner cabin environment: contaminant measurements, health risks and mitigation options. Washington: US Department of Transportation, 1989.

6 Crawford WA, Holcomb LC. Environmental tobacco smoke (ETS) in airliners-a health hazard evaluation. Aviat Space Environ Med 1991;62:580-6.

evaluation. Aviat Space Environ Med 1991;62:580-6.
US Surgeon General. The health consequences of involuntary smoking. Rockville, Maryland: US Department of Health and Human Services, 1986.

Department of Health and Human Services, 1986.
National Academy of Science. The airliner cabin environment-air quality and safety. Washington, DC: National Academy Press, 1986:8.

9 Harding RM, Mills FJ. Aviation medicine. 3rd ed. London: BMJ Publishing Group, 1993:58-62.
}

\section{Smoking and psoriasis}

\section{Smoking could account for one quarter of all cases}

O'Doherty and MacIntyre first drew attention to the strong link between smoking habits and palmoplantar pustular psoriasis in $1985 .{ }^{1}$ Other studies have suggested that smoking might be an important risk factor for chronic plaque psoriasis as well..$^{2-5}$ Most of these studies have recorded information on smoking and psoriasis simultaneously but have also inquired into smoking habits before the onset of the skin disease. There seems little doubt that smoking and psoriasis are associated, but two critical questions remain unanswered: to what extent is the association a causal one, and how important are the implications for the public?

Though four out of six independent studies have suggested a twofold to threefold increased risk of psoriasis in smokers, ${ }^{2-7}$ these might all be misleading because of confounding by alcohol consumption-which is known to be associated with the initiation and severity of psoriasis. ${ }^{48-10}$ Only two of the reports linking smoking and psoriasis included a control for drinking behaviour. ${ }^{24}$ In these studies, the increased risk of psoriasis in smokers did persist after adjustment for alcohol intake, but the problem of residual confounding remains a concern, especially as both alcohol and smoking have been measured only in terms of recall of events in the distant past. ${ }^{11}$ Further similar case-control studies seem unlikely to resolve this issue unless they are done in societies where alcohol is forbidden and smoking is common.

Two studies showed a dose-response effect with the number of cigarettes smoked, ${ }^{45}$ but one other did not. ${ }^{2} \mathrm{~A}$ finding of functional neutrophil abnormalities in patients with psoriasis who smoked adds some biological plausibility to the link, ${ }^{12}$ but other studies could be called on to support either arm of the hypothesis. ${ }^{11}$ Anecdotal reports suggest that stopping smoking has little effect on the course of psoriasis, but factors that affect incidence may not affect chronicity. Intervention studies are needed to examine the effect of smoking on chronicity of the disease and response to treatment.

If smoking does cause psoriasis the impact on public health could be considerable. A twofold risk of psoriasis in smokers is quoted in most studies. Around $30 \%$ of adults smoke, so about a quarter of all cases of psoriasis could have been precipitated by smoking. For palmoplantar pustular psoriasis as much as half of the cases could be related to smoking. Patients with psoriasis seem to have a high incidence of cancers of the lung and larynx, and one explanation could be smoking. ${ }^{13}$ Smoking might possibly be more important for initiating psoriasis in women ( $\mathrm{K}$ Poikolainen, personal communication, 1993), whereas alcohol might be more important in men. ${ }^{6}$ It is also important to consider psoriasis of early and late onset separately, as the two forms may have different causes.

Any progress in identifying modifiable risk factors for this common and socially disabling disease is to be welcomedand it is more useful than reports of temporary remission with expensive and potentially toxic drugs. Despite the high heritability of psoriasis, manipulation of environmental risk factors such as smoking, alcohol, exposure to streptococci, trauma, drugs, and emotional stress open up the possibility of substantial prevention of the disease in the future. Already the evidence is good enough for clinicians routinely to ask about smoking and alcohol habits in all patients with psoriasis 
and especially those with palmoplantar pustular psoriasis. Prospective clinical studies are needed to see whether stopping smoking makes any difference to the course of established psoriasis. Quite possibly people might be more willing to change their habits because of a current and socially debilitating skin disorder than because of long term risks of cancer and ischaemic heart disease.

HYWEL C WILLIAMS

Wellcome research fellow in dermatoepidemiology

St John's Dermatology Centre,

St Thomas's Hospital,

London SE1 7EH

1 O'Doherty CJ, MacIntyre C. Palmoplantar pustulosis and smoking. BMF 1985;291:861-4.

2 Kavli G, Forde OH, Arnesen E, Stenvold SE. Psoriasis: familial predisposition and environmental factors. $B M \mp 1985 ; 291: 999-1000$.
3 Braathen LR, Botten G, Bjerkdal T. Psoriasis in Norway. Acta Derm Venereol 1989;142(suppl): 9-12.

4 Naldi L, Parazzini F, Peserico A, Fornosa CV, Grosso G, Rossi E, et al. Family history, smoking habits, alcohol consumption and risk of psoriasis. Brf Dermatol 1992;127:212-7.

5 Mills CM, Srivastava ED, Harvey IM, Swift GL, Newcombe RG, Holt PJA, et al. Smoking habits in psoriasis: a case control study. Br $\mathcal{F}$ Dermatol 1992;127:18-21.

6 Poikolainen K, Reunala T, Karvonen J, Lauharanta J, Karkkainen P. Alcohol: a risk factor for psoriasis? BMF 1990;300:780-3.

7 Paljan D, Kansky A, Cividini-Stranic E. Psychosomatic factors influencing the course of psoriasis Acta Derm Venereol 1984;113(suppl):121-2.

8 Monk BE, Neill SM. Alcohol consumption and psoriasis. Dermatologica 1986;173:57-60.

9 Chaput J-C, Poynard T, Naveau S, Penso D, Durrmeyer O, Suplisson D. Psoriasis, alcohol, and liver disease. $B M 7$ 1985;291:25.

10 Gupta MA, Schork NJ, Gupta AK, Ellis CN. Alcohol intake and treatment responsiveness of psoriasis: a prospective study. $\mathcal{F}$ Am Acad Dermatol 1993;28:730-2.

11 Davey Smith G, Phillips AN. Confounding in epidemiological studies: why "independent" effects may not be all they seem. $B M 7$ 1992;305:757-9.

12 Sonnex TS, Carrington P, Norris P, Greaves MW. Polymorphonuclear leucocyte random migration and chemotaxis in psoriatic and healthy adult smokers and non-smokers. $\mathrm{Br} \mathcal{F}$ Dermatol migration and chem.

13 Jorgen HO, Moller H, Frentz G. Malignant tumors in patients with psoriasis. $f$ Am Acad Dermatol 1992;27:716-22.

\section{Palliative chemotherapy for advanced non-small cell lung cancer}

\section{Time to reappraise its role}

Lung cancer was one of the first cancers to be treated with chemotherapy, back in the late 1940 s. $^{1}$ Yet today lung cancer (other than small cell tumours) remains the Cinderella of cancer medicine, left behind as chemotherapy is increasingly used for other neoplasms. Palliative radiotherapy can provide good relief of localised symptoms for patients with inoperable disease. $^{2}$ Sooner or later, however, most patients develop metastatic disease, and the message they receive remains, "I'm sorry, there's nothing further we can do." A recent survey of chest physicians, surgeons, and oncologists in Britain showed chemotherapy was offered to only $8 \%$ of patients with non-small cell lung cancer and actually given to only 5\% (Cancer Research Campaign, data on file, 1991). Is this nihilism justified?

Advanced non-small cell lung cancer certainly lacks the chemosensitivity - sometimes dramatic-of the small cell type, but it is by no means completely resistant to drugs. Response rates of $30-40 \%$ are consistently reported with modern chemotherapy regimens, ${ }^{3}$ and more intensive schedules have achieved responses in over half of patients. ${ }^{4}$ These results may seem modest, but they are beginning to approach the response rates seen in advanced breast cancer, where for many years palliative chemotherapy has been widely accepted as having a place. Preoperative chemotherapy for marginally operable non-small cell lung cancer provides a similar comparison. Here response rates of almost $70 \%$ have been reported, with complete resolution of histological changes in $14-19 \%$ of patients who had subsequent surgery ${ }^{5}$; these results are again similar to those of preoperative chemotherapy for early breast cancer, both in our own experience and elsewhere, ${ }^{7}$ and argue against non-small cell lung cancer being considered resistant to drugs.

The impact of chemotherapy on survival in patients with advanced non-small cell lung cancer has been better studied than that for many other common cancers. In an overview of seven randomised trials comparing chemotherapy with best supportive care three showed a survival benefit in favour of chemotherapy, with a similar but non-significant trend in survival in all the others; the overview analysis confirmed a benefit in favour of chemotherapy. ${ }^{8}$ The effect was not large - the average improvement was around three monthsbut even this is more than has been shown for some "standard" treatments such as chemotherapy for advanced breast cancer and palliative radiotherapy in non-small cell lung cancer.
In this disease, which is so difficult to treat, neither encouraging response rates nor even improved survival necessarily imply real clinical benefit. The key question is whether chemotherapy makes patients with lung cancer feel better. Cancer specialists have taken far too long to start asking that question, which may partly explain why attitudes to chemotherapy for this disease remain so negative in Britain. A few years ago our unit began - belatedly - to measure not just the objective response seen on the $x$ ray film but the subjective symptomatic response. The results surprised us. We found that around $70 \%$ of patients treated with a simple schedule of moderate dose chemotherapy reported relief of symptoms including malaise, dyspnoea, cough, and pain. ${ }^{9}$ We have subsequently confirmed our results in a much larger series of patients, and others have reported similar findings. ${ }^{10}$

I suspect there is another problem too-unease at the perceived high costs of palliative chemotherapy in so common a cancer. Such concern is understandable, but it may well be based on a false premise. Chemotherapy represents only a small fraction of the total cost of care for a patient with advanced cancer; in one study of patients with breast cancer it was less than $10 \% .{ }^{11} \mathrm{~A}$ trial in Canada showed that chemotherapy in non-small cell lung cancer not only prolonged survival compared with best supportive care alone but actually reduced the overall costs of care. ${ }^{12}$ This was achieved because chemotherapy (which is relatively cheap) reduced the number of inpatient days (which are very expensive) required for control of symptoms. Too much is said about the allegedly high costs of palliative chemotherapy, and not enough careful research is done into the overall cost effectiveness of such treatment.

Chemotherapy still has a long way to go in non-small cell lung cancer. Its value as adjuvant treatment after surgery and as primary treatment for locally advanced disease before radiotherapy is being investigated. ${ }^{1314}$ For patients with advanced and metastatic disease the best way forward is through further clinical trials looking at new drug schedules and using as end points cost effectiveness and validated quality of life measures (such as the quality of life questionnaire developed by the European Organisation for Research on the Treatment of Cancer).

Clinicians must continue to use their common sense: chemotherapy is inappropriate for frail or chronically ill patients with low performance status. But there is now good 